\title{
ANÁLISE DAS ESTRADAS VICINAIS DO DISTRITO DE BONFIM DE FEIRA - FEIRA DE SANTANA (BA)
}

\author{
$\underline{\text { Igor Ferreira de Almeida }}{ }^{1}$; Gracinete Bastos de Souza ${ }^{2}$; Juliele Nascimento Jesus ${ }^{3}$; \\ Nadine de Jesus Santos ${ }^{4}$ \\ 1. Bolsista PROBIC/UEFS, Graduando em Engenharia Civil, Universidade Estadual de Feira de Santana, e-mail: \\ igor.almeidaig@gmail.com \\ 2. Orientadora, Departamento de Exatas, Universidade Estadual de Feira de Santana, e-mail: graciesouza@ gmail.com \\ 3. Participante do projeto Integração de Dados dos Aspectos do Meio Físico do Município de Feira de Santana, BA, \\ Departamento de Tecnologia, Universidade Estadual de Feira de Santana, e-mail: njjuliele@gmail.com \\ 4. Participante do projeto Integração de Dados dos Aspectos do Meio Físico do Município de Feira de Santana, BA, \\ Departamento de Tecnologia, Universidade Estadual de Feira de Santana, e-mail: nadinesanttos@gmail.com
}

PALAVRAS-CHAVE: estradas vicinais; mobilidade; Feira de Santana.

\section{INTRODUÇÃO}

As estradas vicinais são vias não pavimentadas, geralmente municipais, que são usadas como principais conexões entre as áreas rurais e os centros urbanos. Apesar de corresponder a uma extensa malha das estradas de rodagem, as estradas de terra são esquecidas e não recebem a devida atenção, desenvolvendo problemas técnicos que dificultam a trafegabilidade.

A população de Bonfim de Feira, distrito do município de Feira de Santana - BA, depende diretamente das estradas vicinais locais para ir ao trabalho, escola, médico, compra e venda de mercadorias e diversas outras atividades que só podem ser feitas na área urbana. Assim como a maioria das estradas não pavimentadas do país, as estradas da região não recebem manutenção devida e a apresentam uma série de problemas.

Buracos, atoleiros, erosões e afloramentos de rocha foram encontrados nas estradas da região de Bonfim em um trabalho realizado por Conceição (2014). Geralmente esses problemas são causados pela deficiência da estrutura da estrada ou no sistema de drenagem e no revestimento estradal.

Esse trabalho tem o objetivo de estudar as principais estradas vicinais de Bonfim de Feira e fazer uma análise dos problemas encontrados, para conhecer suas causas a fim de encontrar sugestões viáveis para a solução desses problemas. As informações obtidas nesse trabalho serão divulgadas para que sejam usadas como instrumento para a melhoria da qualidade de vida da população local.

\section{METODOLOGIA}

Para a realização desse trabalho foi feita uma revisão bibliográfica sobre estradas vicinais, geotecnia e sistemas de drenagem. Fez-se também, um levantamento das informações preexistentes sobre as estradas do distrito de Bonfim de Feira - BA, com um estudo mais detalhado do trabalho de iniciação científica de Conceição (2014) sobre o assunto. O manual técnico para conservação e manutenção de estradas vicinais, publicado pelo Instituto de Pesquisas Tecnológicas do estado de São Paulo (IPT), foi usado como base para encontrar as causas e soluções dos problemas presentes nas estradas. 
Foi realizado um trabalho de campo nas estradas que ligam o distrito de Bonfim à Guariba (distrito de Anguera) e a Cavunge (distrito de Ipecaetá), a fim de verificar a situação atual dessas estradas e observar os aspectos geotécnicos. No trabalho de campo foram coletados pontos com o GPS para uma melhor visualização espacial dos pontos estudados, utilizando o Spring, um software de Sistema de Informações Geográficas (SIG) desenvolvido pelo Instituto Nacional de Pesquisas Espaciais (INPE).

\section{RESULTADOS E DISCUSSÃO}

Foram analisadas as estradas de Bonfim - Guariba, Bonfim - Cavunge, Bom Jardim, Bonfim - Poço, Bom Jardim - São Roque, Estrada para Cachoeira, Quituba - Crueira, Terra Nova - Fazenda Mocambo e Terra Nova - Caboronga, de acordo com as informações obtidas no trabalho de iniciação científica sobre as estradas vicinais de Bonfim de Feira - BA, realizado por Conceição (2014).

$\mathrm{Na}$ maioria das estradas foram encontradas ravinas, buracos, atoleiros e poças d'água. Isso ocorre devido a ausência de sistemas de drenagem, o que impede o escoamento da água para fora da pista de rolamento e acaba causando esses problemas. Foi verificado que as estradas não possuem um abaulamento transversal suficiente para conduzir a água da pista para as valetas laterais, que estão cobertas por vegetação, o que dificulta o escoamento da água (Figura 1).

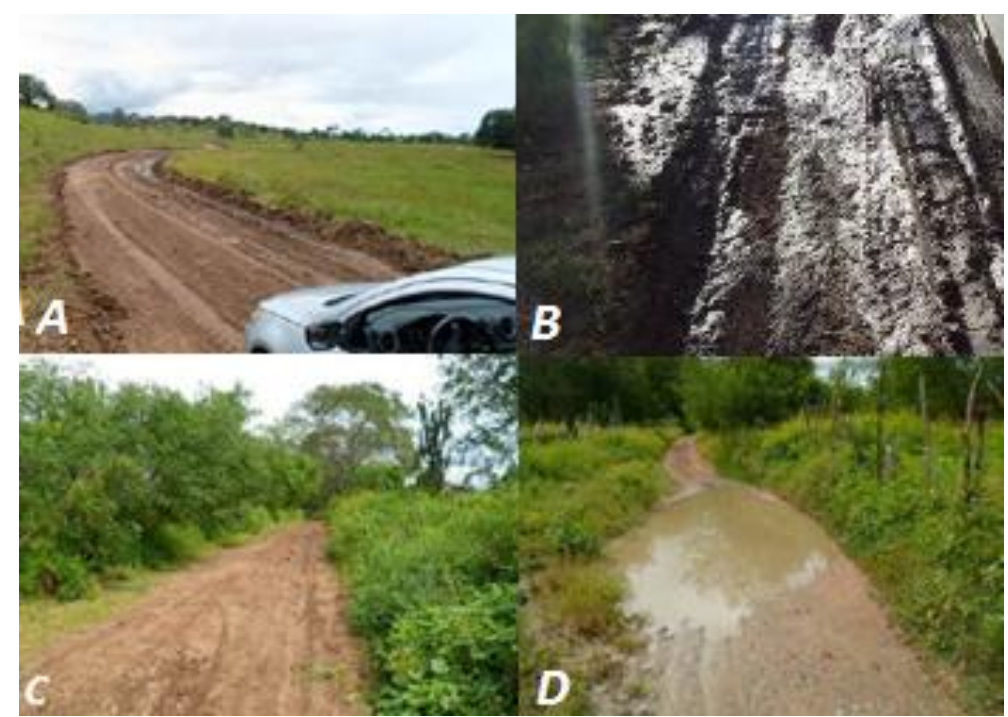

Figura 1: Trechos de algumas estradas estudadas. A- Trecho da estrada Bonfim - Guariba com atoleiro. B- Atolamento na estrada Quituba - Crueira. C e D- Valetas laterais cobertas por vegetação e poça d'água na pista de rolamento da estrada Bom Jardim.

Outro problema encontrado nas estradas foi a grande quantidade de material sólido na pista que causava trepidação nos veículos, como pedregulhos, cascalho solto e afloramentos e fragmentos de rocha. Esse tipo de problema se dá ao fato da camada de solo ser pouco espessa e também à falta de um material ligante para unir os fragmentos soltos. A melhor solução para esse problema é fazer um revestimento primário, que é a mistura de material ligante (argila) com um material granular (geralmente cascalho). O revestimento primário serve ainda como tapume para buracos e fissuras de erosão. A estrada Terra Nova - Mocambo foi a que mais apresentou problemas com material solto na pista e afloramentos de rocha, o que faz o tráfego da estrada ser totalmente incômodo devido à intensa turbulência (Figura 2). 


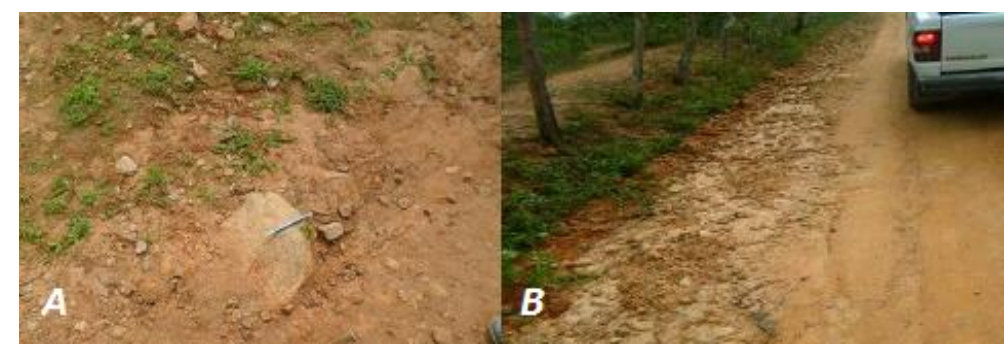

Figura 2: Estrada Terra Nova - Fazenda Mocambo. A- Afloramento de rochas. B- Pedregulhos na lateral da estrada.

Em março de 2017 foi realizado um trabalho de campo em duas estradas estudadas anteriormente, as estradas de Bonfim - Guariba e Bonfim - Cavunge, com o objetivo de verificar a situação atual dessas estradas.

$\mathrm{Na}$ estrada de Bonfim - Guariba foi observada uma grande quantidade de rocha fraturada e afloramentos de rochas, além de erosões na lateral da estrada. A estrada possui alguns elementos de drenagem, como bueiros e uma ponte por onde passava o rio Cavaco, que possui algumas rachaduras e necessita de manutenção. Como esse trabalho de campo foi realizado em época de seca, não foram vistos sinais de atoleiros, poças d'água e vegetação na pista. No geral, a estrada apresentou boas condições de tráfego e aparenta ter passado por recente manutenção.

Já na estrada Bonfim - Cavunge, foi observado muito pedregulho solto e rochas aflorantes. Algumas erosões também foram encontradas, devido ao fato do solo ser muito arenoso. Faz-se necessário a mistura de um material ligante no revestimento para que o material granular não fique solto e cause trepidação. Outro problema é a falta de drenagem adequada. O único bueiro encontrado na estrada estava entupido de lixo, assim, deve-se fazer a limpeza do bueiro e das canaletas, pois o solo da estrada é arenoso e menos resistente à erosão.

A partir dos pontos coletados com o GPS elaborou-se um mapa de distribuição espacial dos pontos no Spring. As estradas foram importadas da Base Cartográfica do Estado da Bahia, disponibilizada em CD pela Superintendência de Estudos Econômicos e Sociais da Bahia - SEI, 2008.

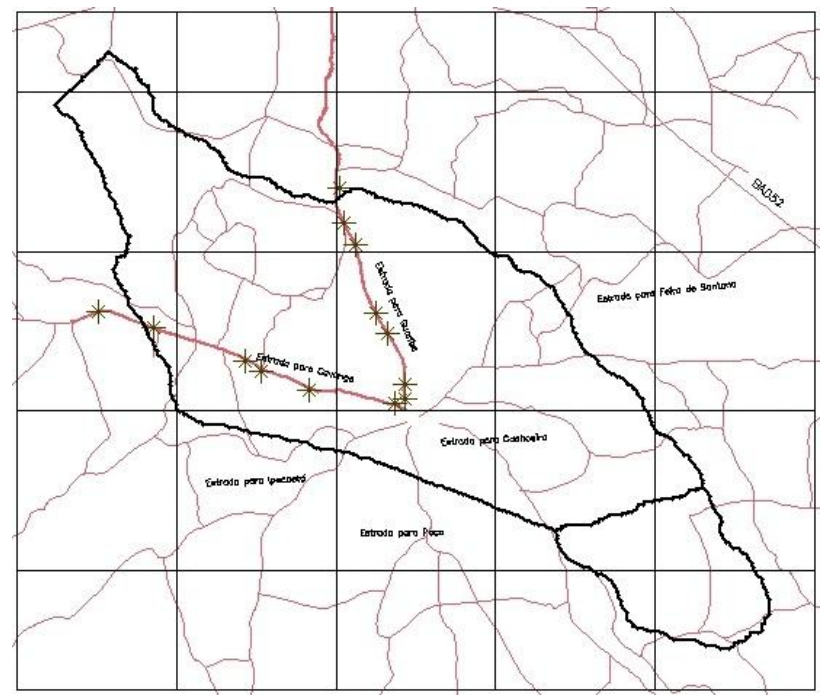

Figura 3: Visão espacial dos pontos das estradas vicinais de Bonfim de Feira elaborado no Spring. 


\section{CONCLUSÃO}

Com base no que foi estudado e analisado no decorrer do trabalho de pesquisa, conclui-se que as estradas vicinais do distrito de Bonfim de Feira - BA apresentam muitos problemas estruturais, causados geralmente pelo deficiente sistema de drenagem e pelo revestimento inadequado.

As estradas precisam primeiramente melhorar o sistema de drenagem, a partir do aumento do abaulamento lateral da pista, limpeza das valetas laterais que estão cobertas por vegetação, pedras ou lixo, e limpeza e manutenção de bueiros, pontes e outras passagens d'água. O próximo passo é dar atenção para os buracos, erosões, afloramentos de rocha e material granular solto, que devem ser cobertos por uma camada de revestimento composta por material ligante e granular (argila e cascalho), que tem a finalidade de tapar as imperfeições e fixar o material solto.

A partir do trabalho de campo foi possível observar que muitos problemas de algumas estradas não foram resolvidos dentro de um período de três a quatro anos, o que mostra que essas estradas não recebem manutenção devida. Esse trabalho teve o objetivo de analisar esses problemas e sugerir soluções, para assim divulgar informações que possam ser úteis para a melhoria das vias não pavimentadas da região.

\section{REFERÊNCIAS}

CABRAL, Érika Santos Pinto. ESTUdO DE CASO SOBRE CONSERVAÇÃO DE RODOVIAS NÃO PAVIMENTADAS - MG-161: 2011. 55f. Relatório Técnico Científico (Pós-graduação em Engenharia de Estradas com Ênfase em Drenagem), Faculdade de Engenharia de Minas Gerais, Belo Horizonte, Dezembro, 2011.

CONCEIÇÃO, Matheus de Oliveira A. MAPEAMENTO E CARACTERIZAÇÃO DAS ESTRADAS VICINAIS DO DISTRITO DE BONFIM DE FEIRA - FEIRA DE SANTANA (BA). Feira de Santana, Bahia. Universidade Estadual de Feira de Santana. Relatório de Iniciação Científica, 2014.

DNIT. Departamento Nacional de Infra-Estrutura de Transportes. Manual de drenagem de Rodovias- 2. ed. Diretoria de Planejamento e Pesquisa. Coordenação Geral de Estudos e Pesquisa. Instituto de Pesquisas Rodoviárias. Rio de Janeiro, 2006.

SANTOS, Álvares Rodrigues dos et al. Estradas vicinais de terra -Manual Técnico para Conservação e Recuperação. São Paulo: Instituto de Pesquisas Tecnológicas do Estado de São Paulo S. A., 1988.

SILVA, Taciano Oliveira da et al. AVALIAÇÃO DO SUBLEITO DE RODOVIAS VICINAIS DE BAIXO VOLUME DE TRÁFEGO POR MEIO DE ENSAIOS GEOTÉCNICOS. Revista Árvore, Viçosa-MG, v.35, n.4, p.825-833, 2011

SPRING: Integrating remote sensingand GIS by object-oriented data modeling. Camara G, Souza RCM, FreitasUM, Garrido J Computers \& Graphics, 20: (3) 395-403, May-Jun 1996. 